\title{
Аномальное краевое свечение ZnSe, сильно легированного кислородом
}

\author{
(C) Н.К. Морозова ${ }^{1}$, И.Н. Мирошникова ${ }^{1,2}$ \\ ${ }^{1}$ Национальный исследовательский университет „Московский энергетический институт“, \\ 111250 Москва, Россия \\ ${ }^{2}$ Институт нанотехнологий микроэлектроники Российской академии наук, \\ 119991 Москва, Россия \\ E-mail: morozovank@mail.ru
}

Поступила в Редакцию 11 апреля 2019 г.

В окончательной редакции 22 апреля 2019 г.

Принята к публикации 2 августа 2019 г.

\begin{abstract}
Изучены особенности спектров излучения чистых CVD конденсатов $\mathrm{ZnSe}$, выращенных при избытке селена и сильном легировании кислородом. Исследовано превалирующее в спектрах низкотемпературной катодолюминесценции $\mathrm{ZnSe}(\mathrm{O})$ аномальное краевое свечение 477(490) нм с целью выяснения его природы. Установлена связь этого свечения со стехиометрическим составом $\mathrm{ZnSe}$ и концентрацией растворенного кислорода. Получены данные, свидетельствующие о роли примеси меди. На основе теории антипересекающихся зон представлена зонная модель, объясняющая природу основных полос люминесценции $\mathrm{ZnSe}(\mathrm{O})$ и $\mathrm{ZnSe}(\mathrm{O}, \mathrm{Cu})$ в прикраевой области спектра. Показано, что модель $\mathrm{ZnSe}(\mathrm{O})$ аналогична усиановленной ранее для $\mathrm{ZnS}(\mathrm{O})$ и $\mathrm{CdS}(\mathrm{O})$.
\end{abstract}

Ключевые слова: самоактивированный, стехиометрический, точечные дефекты,изоэлектронные центры, комплексы.

DOI: $10.21883 /$ FTP.2020.01.48775.9136

\section{1. Введение}

Спектры излучения ZnSe достаточно сложны и, кроме того, исследованы в меньшей степени, чем $\mathrm{ZnS}$ или $\mathrm{CdS}$. Поэтому природа многих полос излучения, как и поглощения, не выяснена. Образование двух твердых оксидов $\mathrm{ZnO}$ и $\mathrm{SeO}_{2}$ способствовало тому, что в некоторых работах особенности спектров $\mathrm{ZnSe}$ приписывались влиянию включений оксидов Расшифровка спектров $\mathrm{ZnSe}(\mathrm{O})$ противоречива или отсутствует [1-11].

$\mathrm{C}$ появлением теории антипересекающихся зон (band anticrossing theory - BAC), позволяющей учесть присутствие кислорода, получены объяснения самоактивированного свечения ряда кристаллов $\mathrm{A}^{\mathrm{II}} \mathrm{B}^{\mathrm{VI}}$ и внесены поправки в зонную модель $\mathrm{CdS}(\mathrm{O}), \mathrm{ZnS}(\mathrm{O})$. Это стимулировало данную работу по интерпретации влияния кислорода на спектры краевого свечения селенида цинка при изменении стехиометрии и сильном легировании кислородом.

\section{2. Образцы и методики исследования}

Исследования влияния кислорода на оптические свойства $\mathrm{ZnSe}$ были проведены на наиболее чистых по посторонним примесям монокристаллах и поликристаллическом $\mathrm{ZnSe}$, полученном химическим осаждением из газовой фазы (chemical vapor deposition - CVD) в Институте химии высокочистых веществ [12]. Конденсаты $\mathrm{ZnSe}(\mathrm{O})$ были выращены при контролируемом составе газовой фазы. Общее содержание примесей $<10^{16}-10^{17} \mathrm{~cm}^{-3}$. Общее содержание кислоро- да $[\mathrm{O}] \sim 10^{20} \mathrm{~cm}^{-3}$ контролировалось методом химического газохроматографического анализа. Состав $\mathrm{ZnSe}$ задавался соотношением $\mathrm{H}_{2} \mathrm{Se} / \mathrm{Zn}$. Кислород вводился в газовый поток до 4-4.3\%. Контроль кристаллической структуры, микросостава, отсутствия скоплений избыточных компонентов и оксидов, осуществлялся по результатам электронно-микроскопических исследований в растровом электронном микроскопе (РЭМ). Методики исследования и контроля содержания примесей описаны в работах $[5,9,13]$.

Анализ и коррекция зонной модели $\mathrm{ZnSe}(\mathrm{O})$ в соответствии с теорией ВАС в данной работе выполнены с учетом ранее полученных нами данных. Это широкий набор спектров катодолюминесценции (КЛ) при 80-300 К и импульсной катодолюминесценции (ИКЛ) из объема кристалла при 300 . Использованы также результаты измерения поглощения, отражения, спектров возбуждения. На основании расчета равновесия собственных точечных дефектов и зависимости свечения от состава кристаллов $\mathrm{ZnSe}$ было определено строение акцепторных центров, связанных с присутствием растворенного $\mathrm{O}_{\mathrm{Se}}$ кислорода в решетке самоактивированного $\mathrm{ZnSe}(\mathrm{O})$.

\section{3. Эксперимент}

Предварительные исследования чистого по иновалентным примесям $\mathrm{ZnSe}$, не легированного специально кислородом, подтвердили имеющиеся в литературе данные для типичных спектров люминесценции.

На рис. 1 приведены спектры катодолюминесценции и импульсной катодолюминесценции парофазного монокристалла $(1,2)$ и CVD конденсата $(3,4) \mathrm{ZnSe}(\mathrm{O})$. 
Как видно, спектры включают узкие и интенсивные коротковолновые экситонные полосы: 444 нм при $80 \mathrm{~K}$ (или 461 нм при $300 \mathrm{~K}$ ), которые близки по положению свободному экситону чистого $\mathrm{ZnSe}[5,9]$.

Серия эквидистантных полос с головной компонентой 460 нм (рис. 1, кривая 1) представляет характерное при низких температурах „краевое“ (или SAL [6]) свечение $\mathrm{ZnSe}$ на мелких центрах $\left\{\mathrm{Zn}_{i}^{2+} V_{\mathrm{Zn}}^{2-}\right\}^{0}$. По структуре серии эквидистантных полос энергия оптического LO фонона определена как $\sim 30$ мэВ.

Более длинноволновые (ДВ) широкие полосы соответствуют самоактивированному SA излучению, обязанному глубоким кислородным центрам $[5,6]$.
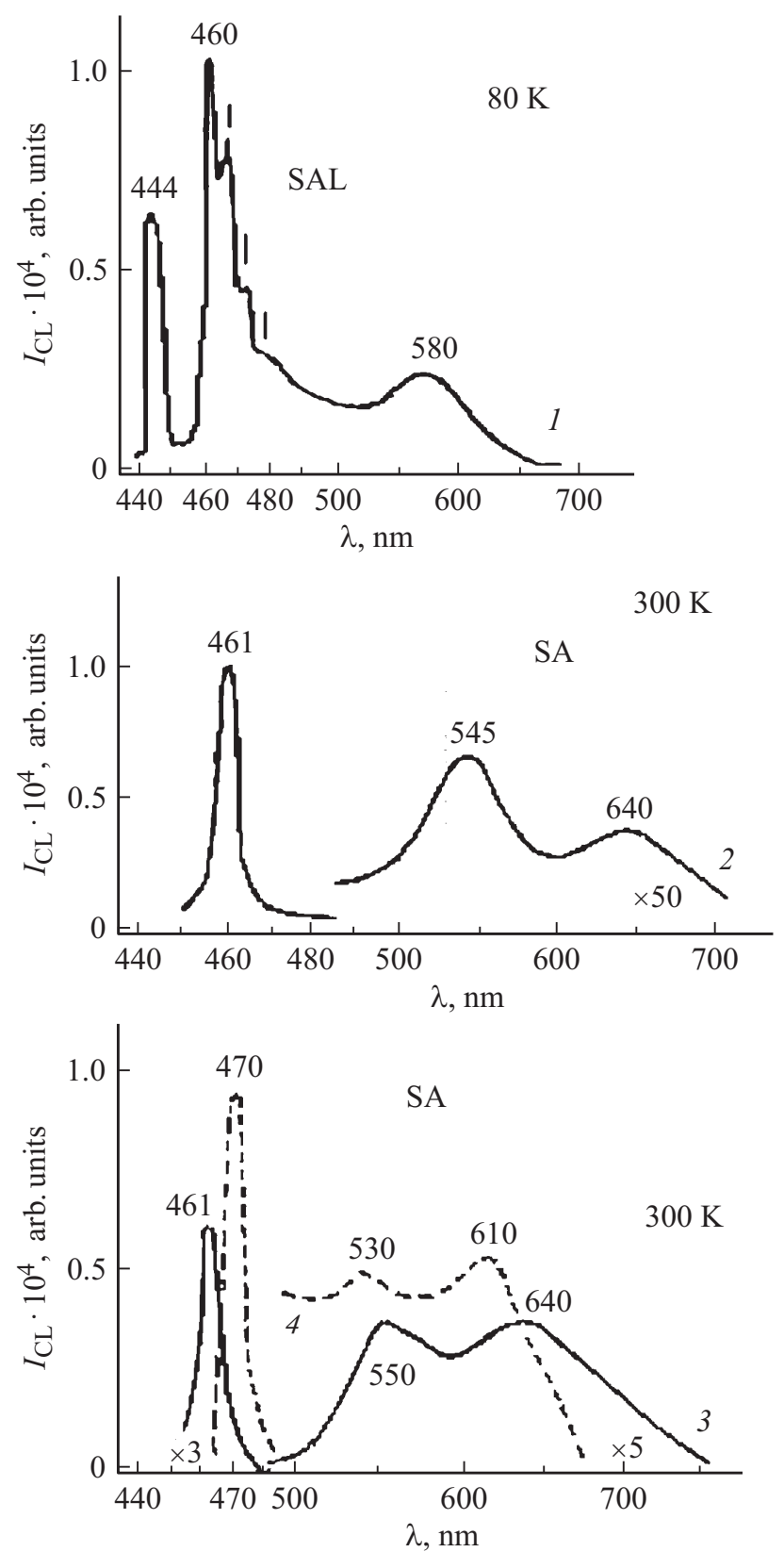

Рис. 1. Спектры КЛ (кривые 1-3) и ИКЛ (кривая 4) самоактивированного $\mathrm{ZnSe}(\mathrm{O})$. Плотность возбуждения составляла $10^{22}$ и $10^{25} \mathrm{~cm}^{-3} \mathrm{c}^{-1}$ для КЛ $(1-3)$ и ИКЛ (4) соответственно.
Предметом многочисленных исследований являлась природа краевого свечения в материалах группы $\mathrm{A}^{\mathrm{II}} \mathrm{B}^{\mathrm{VI}}$. $\mathrm{C}$ позиций теории ВАС впервые самоактивированное $\mathrm{SAL}$ краевое свечение $\mathrm{ZnSe}(\mathrm{O})$ было исследовано в работах [5-6,8]. В этих работах краевое свечение $\mathrm{ZnSe}(\mathrm{O})$ сопоставлялось переходам из двух подзон $E_{+}$и $E_{-}$расщепленной зоны проводимости как две ветви излучения. Эти данные были положены в основу описания зонной модели кристалла $\mathrm{ZnSe}(\mathrm{O})$ в работе [5].

Несоответствие выявлено в последующих работах этого направления, в частности для $\mathrm{CdS}$ [14]. Было показано, что центры краевого свечения $\mathrm{CdS}$ связаны с вполне определенными собственными точечными дефектами кристалла. Как и для $\mathrm{ZnSe}$ [6-9], это комплексы типа $\left\{V_{\mathrm{Cd}}^{2-} \mathrm{Cd}_{i}^{2+}\right\}^{0}$, которые создают мелкие квазиакцепторные уровни $0.12 \pm 0.02$ эВ от потолка валентной зоны. Они типичны для области кристаллов вблизи стехиометрического состава. Краевое свечение SAL обусловлено рекомбинацией свободных электронов подзоны $E_{-}$с дырками, захваченными акцепторными SAL центрами. При этом свечение связано только с нижней подзоной $E_{-}[5,14]$. Излучение из высокоэнергетической $E_{+}$подзоны попадает в область фундаментального поглощения кристалла и поглощается. Результаты подтвердились на монокристаллах $\mathrm{ZnS}(\mathrm{O})$ в работе [15].

Данная работа ставила целью проверить эти выводы для $\mathrm{ZnSe}(\mathrm{O})$. На рис. 2, а представлена построенная нами схема энергетических переходов с мелкими SALуровнями, типичными для кристаллов стехиометрического состава с малой концентрацией кислорода $[5,6,9]$. Величина смещения подзон на 1 мол\% $\left(2 \cdot 10^{20} \mathrm{~cm}^{-3}\right)$ растворенного кислорода $\mathrm{O}_{\mathrm{Se}}$ в $\mathrm{ZnSe}$ взята равной $100 \mathrm{мэВ} \mathrm{[5].} \mathrm{Положение} \mathrm{кислородного} \mathrm{уровня} E_{\mathrm{O}}$ по отношению ко дну зоны проводимости 0.11 эВ, а также уровня SAL-центров в соответствии с литературными данными в работе [5].

Приведенная на рис. 2 зонная модель позволяет идентифицировать переходы, определяющие краевое SAL свечение $\mathrm{ZnSe}(\mathrm{O})$. Действительно, так как известны ширина запрещенной зоны чистого $\mathrm{ZnSe} E_{c}=2.813$ эВ $(80 \mathrm{~K})$ и положение рекомбинационного уровня SAL свечения $\sim 0.1$ эВ $[5,3,9]$, то, очевидно, что полосу 460 нм (2.695 эВ) можно сопоставить только переходам из низкоэнергетической $E_{-}$подзоны на уровни SAL-центров. Излучение из высокоэнергетической $E_{+}$ подзоны приходится на область фундаментальной абсорбции $\mathrm{ZnSe}$. Поэтому оно не должно наблюдаться в спектрах излучения. Эта закономерность для краевого свечения $\mathrm{ZnSe}(\mathrm{O})$ с основной линией 460 нм не отличается от выявленной нами на кристаллах $\mathrm{CdS}$ и $\mathrm{ZnS}$, что позволило внести поправки для SAL свечения $\mathrm{ZnSe}(\mathrm{O})$ (см. рис. 2,a) по сравнению с результатами работы [5].

Что касается второго типа само-активированного свечения $\mathrm{ZnSe}(\mathrm{O})$ - $\mathrm{SA}$ на глубоких центрах $\left\{\mathrm{Zn}_{i}^{1+} V_{\mathrm{Zn}}^{2-}\right\}^{1-}$, то в отличие от SAL оно приходится на область пропускания $\mathrm{ZnSe}$. Поэтому реализуются обе 


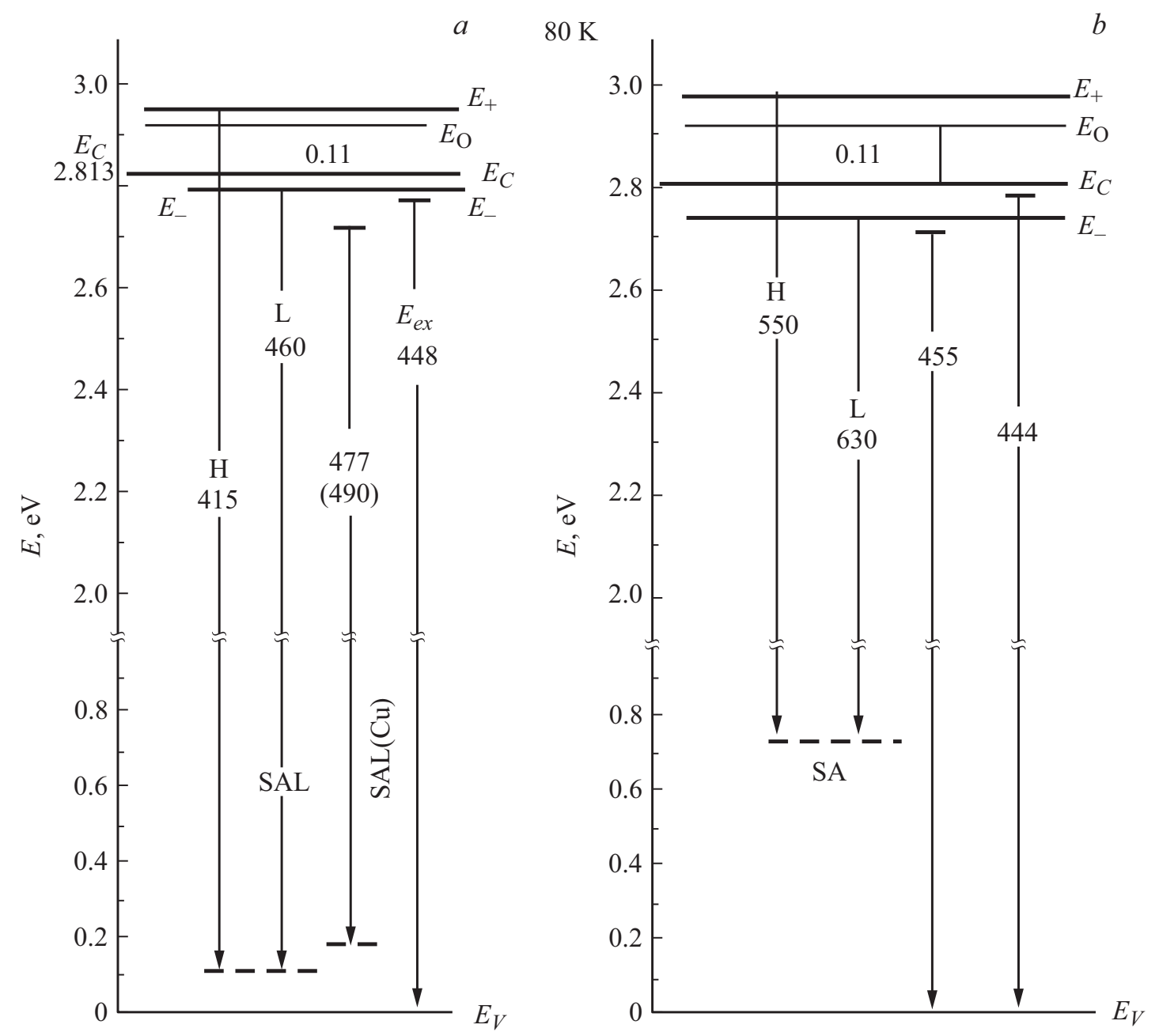

Рис. 2. Модели зонной структуры при 80 Кдля SAL и SA свечения самоактивированного $\mathrm{ZnSe}(\mathrm{O})$ с содержанием растворенного кислорода 0.1 при избытке селена $(a)$ и 0.7 мол\% при избытке цинка $(b)$.

ветви излучения из подзон $E_{-}$и $E_{+}$. Для $\mathrm{ZnSe}(\mathrm{O})-$ это полосы $\mathrm{SA}(\mathrm{L})$ и $\mathrm{SA}(\mathrm{H})$ на рис. $2, b$ или в спектрах рис. 1, (кривая 2). Это свечение $\mathrm{ZnSe}$ характерно для кристаллов с отклонением от стехиометрии к избытку $\mathrm{Zn}$, определяющему повышенное содержание растворенного кислорода $[6,9]$.

Зонная модель SA свечения $\mathrm{ZnSe}$ (см. рис. 2,b) построена для концентрации кислорода $\left[\mathrm{O}_{\mathrm{Se}}\right]=0.7$ мол\% $\left(1.4 \cdot 10^{20} \mathrm{~cm}^{-3}\right)$, которая известна для исследуемых образцов по ДВ сдвигу экситонных полос в спектрах КЛ. Это, например, слабая полоса КЛ 454-455 нм при $80 \mathrm{~K}$ (рис. 3) или полоса импульсной люминесценции (рис. 1, кривая 4) ${ }^{1}$, типичный ДВ сдвиг которой достигал 473 нм при $300 K[9,13]$.

\footnotetext{
${ }^{1}$ Пример ДВ сдвига экситонной полосы с $\left[\mathrm{O}_{\mathrm{Se}}\right] \sim 0.5$ мол\% в спектрах ИКЛ, снятых из объема ( 100 мкм), приводится на рис. 1 (кривая 4). Неизменность спектрального положения узких и интенсивных экситонных линий 444 нм при $80 \mathrm{~K}$ или 461 нм при $300 \mathrm{~K}$ в независимости от $\left[\mathrm{O}_{\mathrm{Se}}\right]$ отражает содержание кислорода в поверхностном обедненном кислородом информационном слое, что детально описано в работе [16].
}

Для изучения влияния повышенного легирования кислородом и селеном на спектры излучения самоактивированного $\mathrm{ZnSe}(\mathrm{O})$ были выращены воспроизводимые по характеристикам конденсаты из области стехиометрии, включающие зоны с различным избытком Se. Кислород вводился в газовую фазу до 4.3\%. Избыток Se и сильное легирование кислородом в процессе роста приводит к существенному изменению в спектрах (рис. 3).

В отличие от предшествующих спектров (см. рис. 1), наблюдается „аномальное“ свечение в области 477-490 нм. Набор узких эквидистантных полос с коротковолновой линией 477 нм и LO фононные повторения разрешаются для начальной части конденсата (рис. 3, a). С продвижением по длине конденсата в спектрах усиливаются LO повторения линии 477 нм, и формируется широкая полоса 490 нм. Тонкая структура ее коротковолновой части размывается, а максимум смещается ко второму или третьему LO повторению основной линии 477 нм (рис. 3, b). При максимальном избытке кислорода превалирует свечение с максимумом $\sim 490$ нм во всей области спектра (рис. 3, c). 

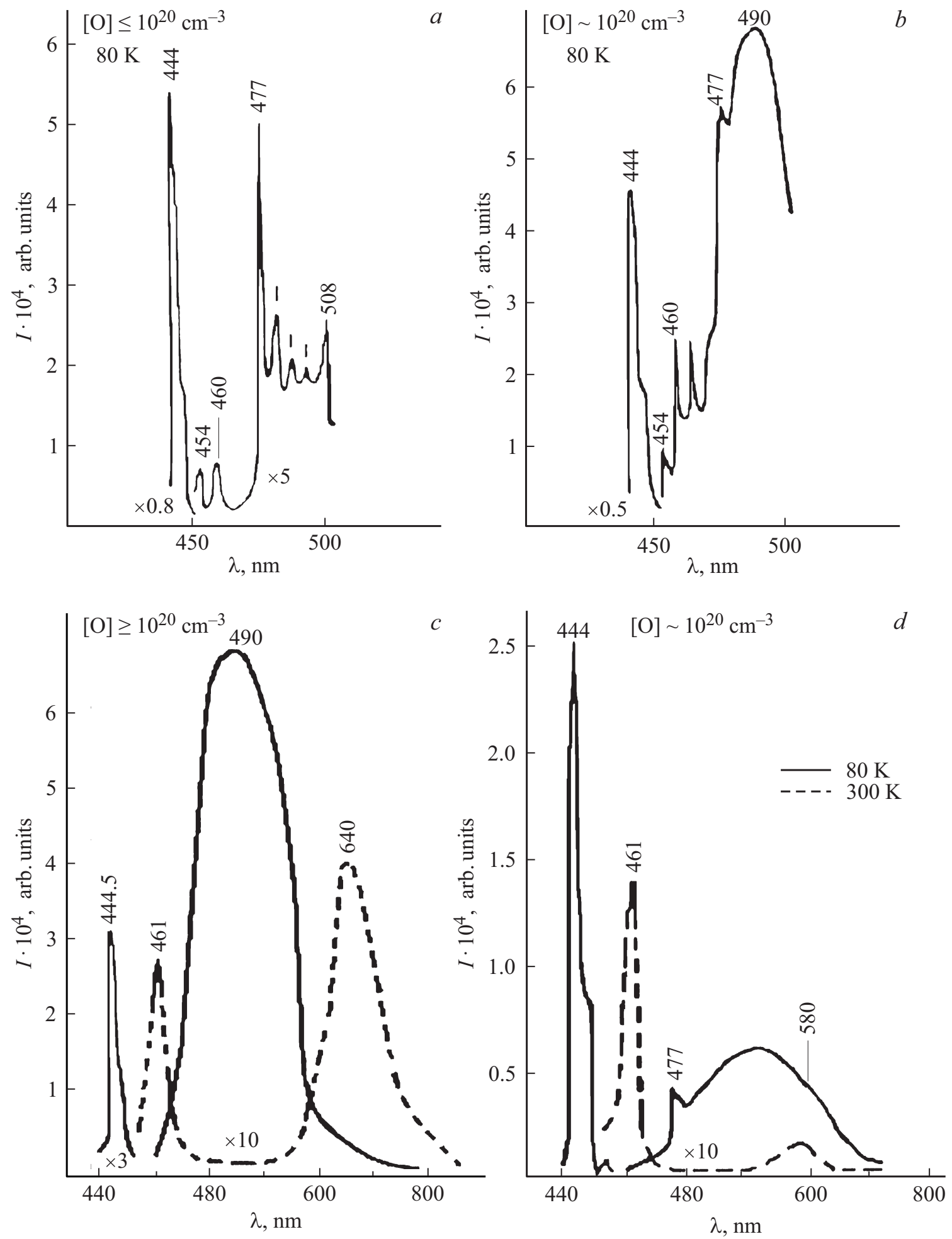

Рис. 3. Спектры КЛ разных участков двух конденсатов $\mathrm{ZnSe}(\mathrm{O})$, сильно легированных в процессе осаждения кислородом, и разном уровне легирования $\mathrm{Se}: a-$ с избытком $\mathrm{Se}, b$ и $c-$ стехиометрического состава, $d-$ с небольшим избытком Zn.

Свечение на длинах волны 477 и 490 нм самоактивированного $\mathrm{ZnSe}(\mathrm{O})$ сравнительно мало изучено $[1,2]$. Определим его как SAL(II). Исследование нами спектров фотовозбуждения люминесценции (ФВЛ) при $80 \mathrm{~K}$ показало, что полосы 477 и 490 нм относятся к одному и тому же центру и характеризуются одним узким максимумом возбуждения 455 нм. Спектры поглощения обнаруживают размытый край дополнительной абсорбции $\sim 448$ нм. Исследована также зависимость смещения полос от температуры и интенсивности возбуждения 
свечения [9]. В общих чертах свойства SAL(II) свечения значительно не отличаются от свойств обычной краевой люминесценции $\mathrm{ZnSe}$ с основной линией 460 нм.

Изменение свечения с повышением температуры представлено на (рис. $3, c, d)$. При $300 \mathrm{~K}$ полоса $\mathrm{SAL}(\mathrm{II})$ не наблюдается. Однако свечение может резко уменьшаться по интенсивности даже при $80 \mathrm{~K}$ с уменьшением избытка $\mathrm{Se}$ (рис. $3, d$ ). В результате при $80 \mathrm{~K}$ возникает слабая SA-люминесценция на глубоких центрах. Эта полоса 640 нм по спектральному положению подтверждает высокую концентрацию растворенного кислорода $\left[\mathrm{O}_{\mathrm{Se}}\right]$ в образцах. Изменение типа свечения $\mathrm{SAL} \rightarrow \mathrm{SA}$ связано c изменением состава кристаллов при уменьшении избытка селена и неоднородностью конденсата.

Изменение состава кристаллов объясняет также усиление полосы 490 нм в спектрах $\mathrm{ZnSe} p$-типа проводимости [1]. Проведенный нами расчет равновесия собственных точечных дефектов для условий роста рассматриваемых CVD конденсатов $\mathrm{ZnSe}[6,8,9]$ показал, что область конденсации охватывает диапазон составов, смещенный от точки стехиометрии к $p$-типу, и можно ожидать сходства их спектров.

В области конденсации собственная дефектная структура кристалла $\mathrm{ZnSe}$ с избытком селена определяется SAL комплексами $\left\{V_{\mathrm{Zn}}^{2-} \mathrm{Zn}_{i}^{2+}\right\}^{0}$, которые не обеспечивают соактивацию для кислорода. Количество растворенного кислорода $\mathrm{O}_{\mathrm{Se}}$ в таких кристаллах $\mathrm{A}^{\mathrm{II}} \mathrm{B}^{\mathrm{VI}}$ даже падает до минимума (без специального легирования кислородом $[5,9,17])$. Однако в полученных для исследования конденсатах, согласно анализам, концентрация кислорода возрастает до $\sim 1$ мол\%.

Сильное легирование кислородом возможно при вхождении в $\mathrm{ZnSe}$ меди, средняя концентрация которой в конденсате $\sim 10^{16} \mathrm{~cm}^{-3}$ и может быть выше в начальной части.

Обнаружение в спектре КЛ второй узкой полосы 508 нм (рис. $3, a$ ) прямо свидетельствует о присутствии $\mathrm{Cu}$, так как эта полоса типична для $\mathrm{ZnSe}$, легированного медью ${ }^{2}[6,7,9]$. В работах по исследованию $\mathrm{ZnSe}$, специально легированного медью [2], узкие полосы излучения, аналогичные 477 и 508 нм, действительно наблюдались как $Y$ и $Z$, без идентификации их природы.

Для объемной и зарядовой компенсации изоэлектронного акцептора $\mathrm{O}_{\mathrm{Se}}$ вхождение меди в междоузлия как донорного дефекта $\mathrm{Cu}_{i}^{+}$обеспечивает образование устойчивого комплекса $\left\{\mathrm{Cu}_{i} \mathrm{O}_{\mathrm{S}}\right\}$. При измерении спектров поглощения и возбуждения в рассматриваемых нами конденсатах обнаруживаются новые уровни $\sim 2.72$ эВ от $E_{V}[8,9]$.

Сопоставление всех экспериментальных фактов с зонной моделью, приведенной на рис. 2 для $\mathrm{ZnSe}(\mathrm{O}, \mathrm{Cu})$, позволяет идентифицировать узкие полосы люминесценции 477 и 508 нм как излучательные переходы с участием уровней $\sim 2.7$ эВ от $E_{V}$ и акцепторных центров

\footnotetext{
2 Линия 508 нм присутствует на рис. $3, a$, а соответствующая ей фононная линия - 520 нм не показана.
}

$E_{\mathrm{SAL}}$ и $E_{\mathrm{SALCu}}$. Не исключено, что уровень 27 эВ определяется краем $E_{-}$подзоны в скоплениях с повышенным содержанием $\left[\mathrm{O}_{\mathrm{Se}}\right]$ и меди.

Кроме того, согласно данным работ $[9,11]$, в спектрах КЛ специально легированного медью $\mathrm{ZnSe}$ двум узким линиям 477 и 508 нм сопутствуют две широкие фононные полосы: 490 и 520 нм, которые наблюдаются одновременно.

Можно полагать, что узкие линии 477 и 508 нм (рис. 2) являются бесфононными составляющими краевого SAL свечения $\mathrm{ZnSe}(\mathrm{O}, \mathrm{Cu})$, а широкие интенсивные полосы 490 и 520 нм - их фононными компонентами.

В заключение отметим, что теория антипересекающихся зон позволяет объяснить как особенности спектров самоактивированного $\mathrm{ZnSeO}_{\mathrm{Se}}$, так и более сложной сисемы $\mathrm{ZnSeO}_{\mathrm{Se}}(\mathrm{Cu})$

\section{4. Заключение}

1. Введена коррекция зонной модели самоактивированного $\mathrm{ZnSe}(\mathrm{O})$, определяющей оптические переходы с участием SAL- и SA-центров.

2. Показано, что краевое свечение SAL в не легированном посторонними примесями $\mathrm{ZnSe}(\mathrm{O})$ связано только с $E_{-}$подзоной, что аналогично исследованному нами ранее подобному свечению кристаллов $\operatorname{CdS}(\mathrm{O})$ и $\mathrm{ZnS}(\mathrm{O})$.

3. На базе собственной дефектной структуры углублено понимание природы аномальных полос 477 (490) нм и 508 (520) нм в спектрах низкотемпературной катодолюминесценции $\mathrm{ZnSe}$ с избытком Se и кислорода.

4. Показано, что возникновение при низкой температуре длинноволнового „аномального“ краевого свечения $\mathrm{ZnSe}$ связано не только с сильным легированием кислородом и селеном, но и с присутствием меди.

\section{Конфликт интересов}

Авторы заявляют, что у них нет конфликта интересов.

\section{Список литературы}

[1] М.Е. Агельманов, А.Д. Левит, Е.И. Панасюк. Неорг. матер., 22 (3), 387 (1991).

[2] R. Triboulet, J.O. Ndap, A. Tromson-Carli, P. Lemasson, C. Morhain, G. Neu. J. Cryst. Growth, 159, 156 (1996).

[3] G.D. Watkins. Bull. Amer. Phys. Soc., 15 (3), 290 (1970).

[4] Д.Д. Недоогло, А.В. Симашкевич. Электрические и люминесцентные свойства ZnSe (Кишинев, Штиинца, 1984).

[5] Н.К. Морозова, Д.А. Мидерос, Н.Д. Данилевич. Кислород в оптике соединений II-VI в свете теории антипересекаюшихся зон. (Saarbrücken, Germany, LAP, 2013).

[6] Н.К. Морозова, И.А. Каретников, В.В. Блинов, Е.М. Гаврищук. ФТП, 35 (1), 25 (2001).

[7] G.B. Stringfellow, R.H. Bube. Phys. Rev., 171 (3), 903 (1968). 
[8] Н.К. Морозова, Д.А. Мидерос, Е.М. Гаврищук, В.Г. Галстян. ФТП, 42 (2), 131 (2008).

[9] В.В. Блинов. Автореф. канд. дис. (М., МЭИ, 2003).

[10] http://earchive.tpu.ru/handle/11683/56199

[11] Н.К. Морозова, Е.М. Гаврищук, И.А. Каретников, В.В. Блинов, В.Г. Галстян, В.С. Зимогорский, Э.В. Яшина. Неорг. матер., 38 (6), 674 (2002).

[12] Г.Г. Девятых, Е.М. Гаврищук, А.И. Даданов. Высокочистые вещества, № 2, 174 (1990).

[13] В.И. Олешко. Автореф. докт. дис. (Томск, ТПУ, 2009).

[14] Н.К. Морозова, Н.Д. Данилевич, В.И. Олешко, С.С. Вильчинская. Изв. вузов. Электроника, 95 (3), 3 (2012).

[15] Н.К. Морозова, И.Н. Мирошникова, В.Г. Галстян. ФТП, 53 (6), 793 (2019)

[16] Н.К. Морозова, Н.Д. Данилевич, В.И. Олешко, С.С. Вильчинская. Изв. вузов. Электроника, 93 (1), 14 (2012).

[17] Н.К. Морозова, Б.Н. Мирошников. ФТП, 52 (3), 296 (2018).

Редактор А.Н. Смирнов

\section{Anomalous edge emission from $\mathrm{ZnSe}$, heavily doped with oxygen}

N.K. Morozova ${ }^{1}$, I.N. Miroshnikova ${ }^{1,2}$

${ }^{1}$ National Research University „Moscow Power Engineering Institute“, 111250 Moscow, Russia

2 Institute of Nanotechnology of Microelectronics,

Russian Academy of Sciences,

119991 Moscow, Russia

Abstract The features of the emission spectra of high-purity CVD ZnSe condensates grown with excess selenium and strong oxygen doping were studied. Investigated prevalent in the spectra of low-temperature cathodoluminescence of $\mathrm{ZnSe}(\mathrm{O})$ abnormal edge emission $477-490 \mathrm{~nm}$ to ascertain its nature. The connection of this luminescence with the stoichiometric composition of $\mathrm{ZnSe}$ and the concentration of dissolved oxygen is established. Obtained data indicating the role admixture of copper. Obtained data indicating the role admixture of copper. Based on the theory of anti-crossing zones, a band model is presented, explaining the nature of the main luminescence bands of $\mathrm{ZnSe}(\mathrm{O})$ in the near edge region of the spectrum. It is shown that the model is identical for $\mathrm{ZnSe}, \mathrm{ZnS}$ and $\mathrm{CdS}$. 